\title{
Effect of seasonality and weather on fracture risk in individuals 65 years and older
}

\author{
Bischoff-Ferrari, H A ; Orav, J E ; Barrett, J A ; Baron, J A
}

\begin{abstract}
In this large population-based study, fracture rates for hips, distal forearms, proximal humeri, and ankles were higher in winter than in other seasons, although the winter peak was small for hip fractures ( $\mathrm{p}<0.05$ at all sites). Younger age between 65 and 80, living in warmer states and male gender were associated with increased winter morbidity due to fractures. Introduction: The objective was to investigate seasonal variation in the incidence of four common fractures, and explore the association of weather with risk. Methods: Population-based analysis of individuals age 65 and older, including fractures of the hip, the distal forearm, the proximal humerus and the ankle. Weather information was obtained from the US National Oceanic and Atmospheric Administration website. Results: For all fractures, rates were highest in winter and lowest in summer ( $\mathrm{p}<0.05$ at all sites). Winter peaks were more pronounced in warm climate states, in men, and in those younger than 80 years old. In winter, total snowfall was associated with a reduced risk of hip fracture $(-5 \%$ per 20inches) but an increased risk of non-hip fractures $(6-12 \% ; \mathrm{p}<0.05$ at all sites). In summer, hip fracture risk tended to be lower during sunny weather $(-3 \%$ per 2 weeks of sunny days; $\mathrm{p}=0.13)$, while other fractures were increased $(15 \%$ $20 \% ; \mathrm{p}<0.05)$ in sunny weather. Conclusion: Fractures contribute considerably to winter morbidity in older individuals. Younger age between 65 and 80, living in warmer states and male gender are risk factors for increased winter morbidity due to fractures. Weather affects hip fracture risk differently than the other fractures studied
\end{abstract}

DOI: https://doi.org/10.1007/s00198-007-0364-6

Posted at the Zurich Open Repository and Archive, University of Zurich

ZORA URL: https://doi.org/10.5167/uzh-155913

Journal Article

Published Version

Originally published at:

Bischoff-Ferrari, H A; Orav, J E; Barrett, J A; Baron, J A (2007). Effect of seasonality and weather on fracture risk in individuals 65 years and older. Osteoporosis International, 18(9):1225-1233.

DOI: https://doi.org/10.1007/s00198-007-0364-6 


\title{
Effect of seasonality and weather on fracture risk in individuals 65 years and older
}

\author{
H. A. Bischoff-Ferrari • J. E. Orav • J. A. Barrett • \\ J. A. Baron
}

Received: 23 October 2006 / Accepted: 2 March 2007 /Published online: 24 March 2007

(C) International Osteoporosis Foundation and National Osteoporosis Foundation 2007

\begin{abstract}
Summary In this large population-based study, fracture rates for hips, distal forearms, proximal humeri, and ankles were higher in winter than in other seasons, although the winter peak was small for hip fractures $(\mathrm{p}<0.05$ at all sites). Younger age between 65 and 80, living in warmer states and male gender were associated with increased winter morbidity due to fractures.

Introduction The objective was to investigate seasonal variation in the incidence of four common fractures, and explore the association of weather with risk.
\end{abstract}

Funding Supported by fellowships from the Harvard Hartford Foundation, from the Swiss Foundation for Nutrition Research, and the International Foundation for the Promotion of Nutrition Research and Nutrition Education.

H. A. Bischoff-Ferrari $(\bowtie)$

Department of Rheumatology and Institute of Physical Medicine, University Hospital Zurich,

Gloriastrasse,

258091 Zurich, Switzerland

e-mail: hbischof@hsph.harvard.edu

H. A. Bischoff-Ferrari

Department of Nutrition, Harvard School of Public Health, Boston, MA, USA

J. E. Orav

Department of Clinical Epidemiology,

Harvard School of Public Health,

Boston, MA, USA

J. E. Orav

Department of Biostatistics, Harvard School of Public Health, Boston, MA, USA

J. A. Barrett · J. A. Baron

Department of Medicine and Department of Community

and Family Medicine, Dartmouth Medical School,

Lebanon, NH, USA
Methods Population-based analysis of individuals age 65 and older, including fractures of the hip, the distal forearm, the proximal humerus and the ankle. Weather information was obtained from the US National Oceanic and Atmospheric Administration website.

Results For all fractures, rates were highest in winter and lowest in summer ( $p<0.05$ at all sites). Winter peaks were more pronounced in warm climate states, in men, and in those younger than 80 years old. In winter, total snowfall was associated with a reduced risk of hip fracture $(-5 \%$ per 20 inches) but an increased risk of non-hip fractures (6-12\%; $\mathrm{p}<0.05$ at all sites). In summer, hip fracture risk tended to be lower during sunny weather $(-3 \%$ per 2 weeks of sunny days; $\mathrm{p}=0.13)$, while other fractures were increased $(15 \%-20 \%$; $\mathrm{p}<0.05$ ) in sunny weather.

Conclusion Fractures contribute considerably to winter morbidity in older individuals. Younger age between 65 and 80 , living in warmer states and male gender are risk factors for increased winter morbidity due to fractures. Weather affects hip fracture risk differently than the other fractures studied.

Keywords Elderly · Fracture risk · Race/ethnicity · Seasonality $\cdot$ Weather

\section{Introduction}

Excess winter morbidity and mortality continue to be important public health problems, especially among older persons [1-3]. In addition to clear seasonal variations in respiratory [2-5] and cardiovascular diseases [6], fractures of the hip [7-13] and distal forearm [14] contribute to high winter morbidity rates in older persons. 
Some studies indicate that falls due to snow and ice may play an important role in seasonality of fractures $[8,9]$. This may explain an "epidemic" of distal forearm fractures documented during ice storms [15]. Thus, one cause of the increased fracture risk in winter compared to summer may be that older persons are more likely to slip and fall during periods of snow and ice [15]. These factors may be particularly important for fracture types that tend to occur out-of-doors in active older persons [16-18]. Hip fractures, which mostly occur indoors [19-21], may be less affected by snow and ice. However, hip fracture risk may be indirectly influenced by cold weather, since some studies suggest that susceptibility to falls and injury in older individuals increases with hypothermia [19, 22]. In addition, independent of temperature, decreased vitamin $\mathrm{D}$ levels in winter may contribute to muscle weakness [23], falls [24, 25] and bone fragility [26, 27].

Little else is known about the impact of seasonality on fracture risk, in particular whether seasonal patterns differ by fracture types, age, gender or latitude. Furthermore the associations between fracture risk and weather factors such as temperature and snowfall are not well defined. To clarify these issues, we studied seasonality patterns of four common fracture types and evaluated whether these patterns differs by age (6580 or older), warm and cold climate states in the US, and three weather variables (snowfall, sunshine and temperature).

\section{Methods}

As previously described [28, 29], fractures were studied using data from the standard $5 \%$ sample of the US Medicare population, investigating beneficiaries over age 65 and residing in the 50 U.S. states during the four years July 1, 1986-June 30, 1990. This sample is based on random selection of the terminal digits of the Health Insurance Claim Number of individuals eligible for Medicare benefits [30]. The Medicare program covers the vast majority of elderly Americans. In 1985, just before the beginning of our study period, the Medicare population included about $96 \%$ of the US population over age 65 [30]. Thus results of our $5 \%$ sample generalize well to the population age 65 and older residing in the US. Data extracted from Medicare claims were used to identify those who had a fracture of interest. Only individuals who were enrolled in both basic Medicare (Part A: Hospital), and supplementary coverage (Part B: Physician Charges) were included so that both sources of information could be used to identify fracture occurrence. Since enrollees in Health Maintenance Organizations (HMO's) and those eligible for Medicare because of entitlement to Railroad benefits often have incomplete claims histories, those beneficiaries were also omitted. We used Medicare data in the period 1986-
1990 , when only about $4-5 \%$ of Medicare recipients aged $65+$ were in an $\mathrm{HMO}[30,31]$.

We sought evidence of fractures using coded diagnoses and procedures on claims in the Medicare Provider Analysis and Review (MEDPAR) file, the Part B Medicare Annual Data system beneficiary (BMAD) file for physician claims, and the outpatient file for emergency room and clinic claims. We studied two upper extremity fractures (proximal humerus and distal forearm), and two lower extremity fractures (hip and ankle). Cases with evidence of bone cancer or prior fracture at a given site were excluded.

The claims-based algorithms for the dating and identification of fractures have been described elsewhere [28]. For hip fractures, for example, we accepted a case if either (1) a hospital discharge diagnosis of hip fracture was present (International Classification of Diseases, 9th version (ICD9-CM), diagnosis code 820-820.9), or (2) a physician claim was present that specifically indicated treatment of a hip fracture (Current Procedure Terminology, version 4 (CPT-4), code range 27230-27248) with confirmation by either (a) hospital discharge coding for an appropriate surgical procedure, or (b) at least one other physician claim for a procedure appropriate to hip fracture repair dated within 2 days of the specific claim.

We obtained demographic data regarding Medicare enrollees from the Medicare denominator file; available data included age, race/ethnicity and gender. These data permitted monthly counts of the number of individuals in each state at risk for a fracture within substrata of age ( 5 year age groups between 65 and 89; 90+), gender (male, female), and race/ethnicity (white, black, other and unknown). Weather information by calendar month over 30 to 50 years (depending on the weather station) was obtained from the National Oceanic and Atmospheric Administration website (http://www.noaa.gov). Available data included: (1) snowfall at 275 weather stations (2) sunshine (number of sunny days) at 292 stations, and (3), and mean daily temperature at 283 weather stations. Larger states with the potential for climatic variability were represented with a greater number of weather stations. For example, Vermont and Maryland had only one weather station each, while California had 15, Texas had 20, and Alaska had 22. We used the means of these monthly data points per state over the maximum observation period for each station.

We defined winter as December, January and February; spring as March, April and May; summer as June, July and August; and fall as September, October and November. For each state and month, we averaged data from all weather stations and computed seasonal totals (for snowfall and sunny days) or seasonal means (for temperature). Since findings were similar if weather variables in the capital city or the mean of all weather stations in a given state were used, we present only the latter. We assumed individuals 
were exposed to the weather in their states of residence, even if the fracture was treated in a different state. In a sensitivity analysis, we also considered hip fracture associations among individuals in which the treating hospital was in the same state as the residence. Those were similar to the overall findings and are not presented here.

\section{Statistical analysis}

We used Poisson regression to study the associations of season and weather variables with fracture risk by state, by computing rate ratios and $95 \%$ confidence intervals (CIs). These analyses were based on fracture rates (by age, sex, race/ethnicity, state) for each season. The numerators of the rates were the sum over the four study years of the number of fractures of a particular type occurring during a given season among individuals in a particular age/sex/race stratum. The denominators were the sums of the corresponding populations over the four years of the study. All regression models included season, age, sex and race/ ethnicity. We used as a basic measure of seasonal variation the ratio of fracture rates in winter to those in summer, derived from models that included all four seasons.

In addition to overall analyses, we also evaluated fracture risk among subgroups of the population, including those defined by gender and age (younger persons aged 65-79 and older persons $80+$ ). We were particularly interested in assessing whether seasonal patterns would be accentuated among the relatively frail population (women and those aged $80+$ ) because of its susceptibility to trauma, or whether these patterns would be diminished among this group (perhaps because of avoidance of outside activities during inclement weather). Similarly, we investigated whether the seasonal variation was more pronounced in "cold" states (which we took to be New England, New Jersey, New York, Pennsylvania, Illinois, Indiana, Michigan, Ohio, Wisconsin, Minnesota, North Dakota, South Dakota, Idaho, Montana, Wyoming and Alaska) or in "warm" states (Hawaii, California, Oregon, Washington, Arizona, New Mexico, Florida, Georgia, Alabama, Mississippi and Louisiana).

A 5\% significance level was maintained throughout these analyses. Interactions between season or weather variables and winter-summer swings of hip and non-vertebral fractures, and warm versus cold states, and demographic factors (gender, age, and race) were explored by product interaction terms and Wald tests. Data were analyzed using SASC (Version 8.0).

\section{Results}

A total 69,857 fracture cases were identified: 35,007 at the hip, 16,622 at the distal forearm, 9,708 at the proximal humerus, and 8,520 at the ankle. For each fracture, women comprised the majority of the affected population (78.4 $88.4 \%$ ) (Table 1). Similarly, white race was most prevalent at all fracture sites $(92.6 \%$ to $95.9 \%)$. Fracture risk by gender, age, and race for this national data-set has been described in more detail previously [31-33].

\section{Seasonal variation}

There were significant seasonal variations in fracture risk at all four sites, as shown in Fig. 1 and Table 2. Each of the fractures was significantly more frequent in winter than in any other season, especially summer. Hip fracture had a smaller winter/summer difference than the other three fracture types $(8 \%$ versus about $20 \% ; \mathrm{p}<0.01$ for each comparison).

Both warm and cold climate states had winter peaks for each of the fractures studied (Fig. 2). For hip fracture, the seasonal differences between winter and summer were similar in the two groups of states. However, for fractures of the ankle, the winter/summer variation was significantly larger in warm climate states than in colder states $(p=0.004)$. For fractures of the proximal humerus and distal forearm, the winter summer variation was also greater in warm states, but the differences were compatible with chance.

There was no suggestion that the "frail" population groups had particularly large seasonal variations. In fact, the opposite was the case. Winter peaks were higher in men than in women at all studied fracture sites, particularly for the distal forearm. The winter-summer variation in rates was also higher in Medicare beneficiaries younger than 80 years old than among those who were older. Also, for most fractures, winter peaks appeared to be more pronounced in black individuals than among whites. (see Table 3 for winter/summer relative fracture risks by subgroups of the population).

\section{Weather}

Analyses of the association between weather variables and fracture risk within winter and summer seasons are illustrated in Fig. 3a-c.

In winter, hip fractures showed weather associations that were distinctly different from those for the other fractures. Local snowfall tended to be associated with a decreased risk of hip fracture, but an increased risk of the other fractures. The RR of hip fracture per 20 inches of annual snowfall was 0.95 [95\% CI 0.91-0.99], but the RR's for fractures of the distal forearm, proximal humerus and ankle were significantly elevated (Fig. 3a). Mean winter temperatures were not related to fracture risk at the hip and proximal humerus, while higher winter temperatures were inversely related to risk for the distal forearm (RR per 10 degrees Fahrenheit $=0.95$ [95\% CI 0.92-0.99]) and the 
Table 1 Demographic characteristics of fracture patients, by fracture site

\begin{tabular}{|c|c|c|c|c|c|c|c|c|}
\hline & \multicolumn{2}{|l|}{ Hip } & \multicolumn{2}{|c|}{ Distal forearm } & \multicolumn{2}{|c|}{ Proximal humerus } & \multicolumn{2}{|l|}{ Ankle } \\
\hline & \multicolumn{2}{|c|}{$\mathrm{N}=35,007$} & \multicolumn{2}{|c|}{$\mathrm{N}=16,622$} & \multicolumn{2}{|c|}{$\mathrm{N}=9,708$} & \multicolumn{2}{|c|}{$\mathrm{N}=8,520$} \\
\hline & $\mathrm{N}$ & $\%$ & $\mathrm{~N}$ & $\%$ & $\mathrm{~N}$ & $\%$ & $\mathrm{~N}$ & $\%$ \\
\hline Females & 27,596 & $78.8 \%$ & 14,686 & $88.4 \%$ & 8,170 & $84.2 \%$ & 6,676 & $78.4 \%$ \\
\hline White race & 33,215 & $94.9 \%$ & 15,881 & $95.5 \%$ & 9,305 & $95.9 \%$ & 7,893 & $92.6 \%$ \\
\hline Fractures in winter (all states) & 9,177 & $26.2 \%$ & 4,737 & $28.5 \%$ & 2,635 & $27.1 \%$ & 2,438 & $28.6 \%$ \\
\hline Fractures in summer (all states) & 8,440 & $24.1 \%$ & 3,964 & $23.9 \%$ & 2,192 & $22.6 \%$ & 2,000 & $23.5 \%$ \\
\hline Age (years) 65-69 & 2,482 & $7.1 \%$ & 3,787 & $22.8 \%$ & 1,563 & $16.1 \%$ & 2,742 & $32.2 \%$ \\
\hline Age (years) 70-74 & 4,284 & $12.2 \%$ & 3,698 & $22.2 \%$ & 1,870 & $19.3 \%$ & 2,210 & $25.9 \%$ \\
\hline Age (years) 75-79 & 6,891 & $19.7 \%$ & 3,603 & $21.7 \%$ & 2,071 & $21.3 \%$ & 1,638 & $19.2 \%$ \\
\hline Age (years) 80-84 & 8,322 & $23.8 \%$ & 2,879 & $17.3 \%$ & 2,053 & $21.2 \%$ & 1,035 & $12.2 \%$ \\
\hline Age (years) 85-89 & 7,641 & $21.8 \%$ & 1,743 & $10.5 \%$ & 1,385 & $14.3 \%$ & 567 & $6.7 \%$ \\
\hline Age (years) 90-99+ & 5,387 & $15.4 \%$ & 912 & $5.5 \%$ & 766 & $7.7 \%$ & 328 & $3.8 \%$ \\
\hline
\end{tabular}

ankle (RR per 10 degrees Fahrenheit $=0.87$ [95\% CI $0.83-$ 0.92]) (Fig. 3b). Winter sunshine was not significantly associated with fracture risk at any fracture site (Fig. 3c).

Contrasts in weather associations between hip and the other fracture sites were also seen during the summer. Hip fracture risks were highest in hotter locations (RR per 10 degrees Fahrenheit=1.07 [95\% CI 1.02-1.12]), but higher regional temperatures were associated with a significant decrease in risk of ankle fracture (RR per 10 degrees Fahrenheit $=0.91 \quad$ [95\% CI 0.83-0.996]; Fig. 3b). Hip fracture risk tended to be lower in areas with sunny summer weather (RR per 14 sunny days $=0.97$ (95\% CI 0.94-1.01), but for the other fractures we studied, sunshine exposure was associated with an increased fracture risk (Fig. 3c).
In spring and fall (not displayed in Figures), sunshine showed associations with fracture risk that were broadly similar to those in summer and winter, with a clear contrast between hip fractures and the others. For example, hip fracture risks were lowest during sunny fall weather (RR per 14 sunny fall days $=0.94$ (95\% CI 0.90 0.99); while the RR's for the other fractures were between 1.1 and 1.3 (CI's per 14 sunny days excluded " 1 " at all sites).

\section{Discussion}

In this large population- based study, fracture rates for all the sites studied were higher in winter than in other seasons,

Fig. 1 Relative risks of fractures, by season. Analysis is adjusted for gender, age and race/ethnicity. For all sites, fracture risk in winter was significantly higher than in each of the other seasons $(95 \%$ CI excluded 1 for the comparison of each season with winter)

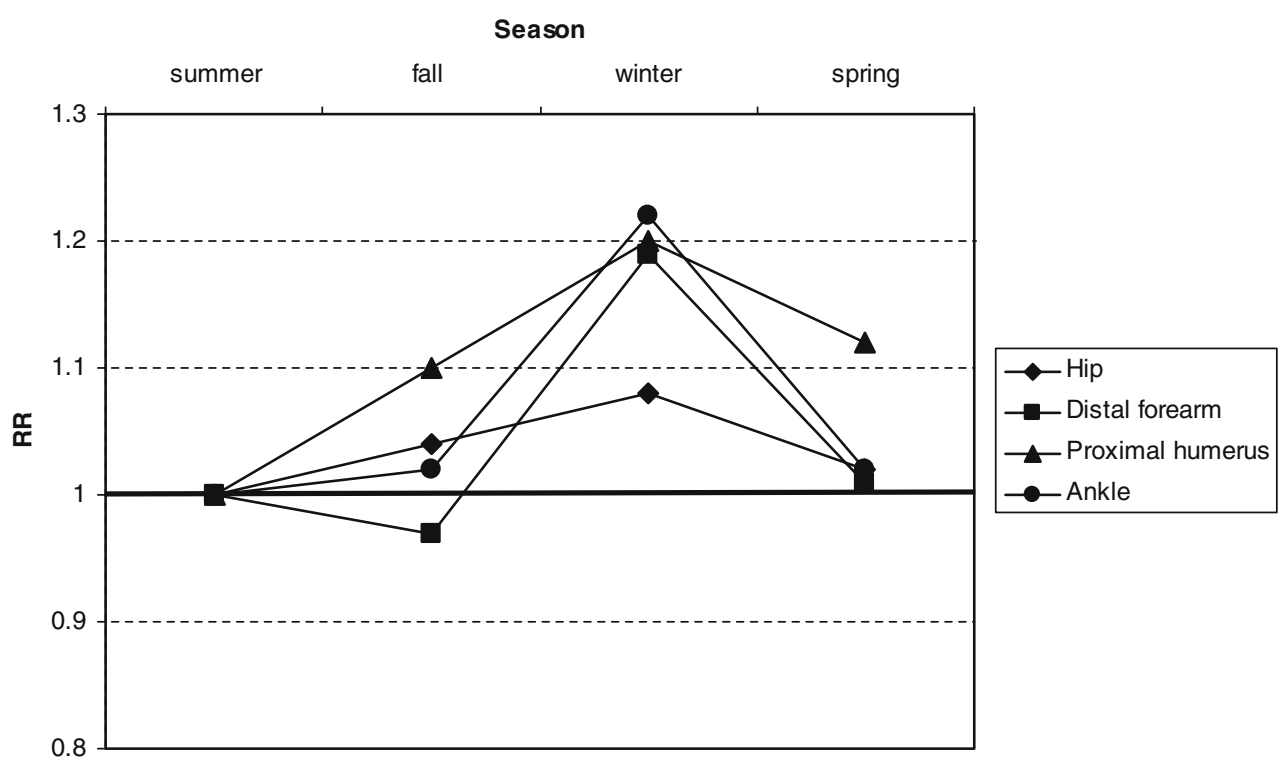


Table 2 Winter/summer relative risks, by fracture type

\begin{tabular}{lll}
\hline Fracture site & \# of Fractures & RR $(95 \%$ CI $)$ \\
\hline Hip & 35,007 & $1.08(1.05-1.12)$ \\
Distal forearm & 16,622 & $1.19(1.14-1.24)$ \\
Proximal humerus & 9,708 & $1.20(1.14-1.27)$ \\
Ankle & 8,520 & $1.22(1.15-1.29)$ \\
\hline
\end{tabular}

RRs are based on Poisson regression models. The model for each fracture site included gender, age, race/ethnicity.

although the winter peak was small for hip fractures. This seasonal pattern was most evident in "warm" states that are only minimally affected by ice and snow. Hip fracture had strikingly different associations with weather than fractures of the distal forearm, proximal humerus, and ankle. For example, regional snowfall and summer sunshine were inversely related to hip fracture risk, but associated with higher rates of the other fractures.

In agreement with our finding, most previous studies have reported a winter peak in hip fracture incidence [713, 34-37], and a few studies have described a similar pattern for fractures of the distal forearm $[9,14]$ and the arm [8]. Our results extend this seasonal pattern to the proximal humerus and ankle, and show that hip fractures have a lower seasonal variation than the other fractures we studied.

Meteorological patterns and fracture risk have been explored by several authors [7, 11, 15, 34, 37], although these studies were largely limited to hip fracture. In contrast to our findings, one study from Sydney, Australia found mean daily temperature to be inversely related to hip fracture risk [11], and other studies reported increased risks of hip fracture with snowy/icy weather [7, 8, 15, 34]. However, in two of these studies [7, 34], the association was essentially limited to younger women or men- groups that comprised only a minority of our fractures [34]. The third study compared 4 days during severe ice storm conditions with four control days with comparable hours of sunshine, an approach which may not be generalizable to normal snow conditions [15]. Corroborating our results on a geographic level are findings indicating a distinct NorthSouth gradient in hip fracture risk, with lower rates in the North of the US, where colder weather is more common $[29,38]$.

It is not entirely clear why hip fracture showed such strikingly different weather and season associations than the other fractures we studied. However, one plausible explanation may be found in the circumstances surrounding these fractures. Hip fractures tend to occur indoors among relatively frail individuals [19-21], while the others tend to occur among more active individuals who are correspondingly more likely to be outdoors [1618]. Clearly, weather would affect the latter group differently than the former [19]. It is likely, for example, that active individuals would expose themselves to adverse weather conditions more readily than their more frail counterparts, thus increasing their risks of ice- and snow-related falls.

A possible corroboration of this hypothesis is suggested by our subgroup analyses, in which individuals who are more likely to be frail and less active (women and individuals aged 80 years and older), had a smaller winter/summer difference in hip fracture risk than the more robust population groups. In fact, two previous studies show that engaging in physical activity more
Fig. 2 Winter/summer relative risks in warm and cold climate states in the US. RRs are based on Poisson regression models adjusted for age, gender and race/ethnicity

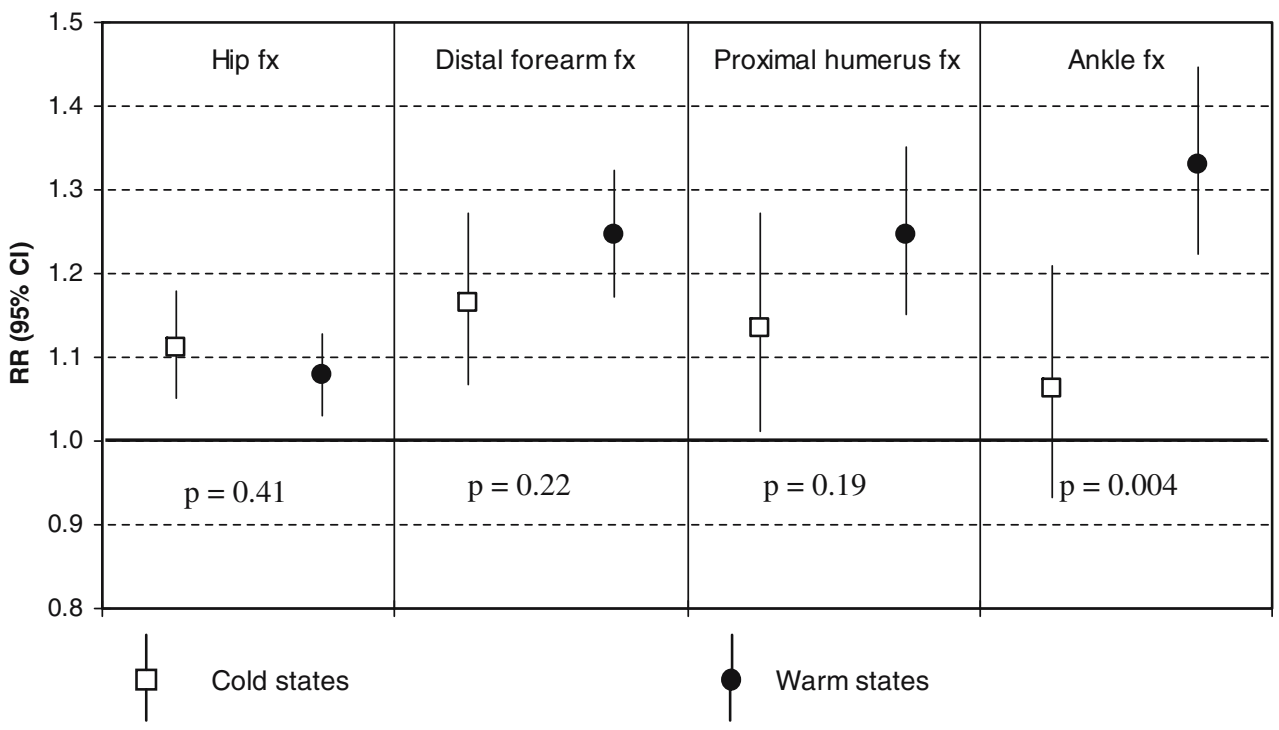


Table 3 Winter/summer relative fracture risks, by fracture type in subgroups of the population

\begin{tabular}{|c|c|c|c|c|c|c|}
\hline \multirow[t]{2}{*}{ Fracture site } & \multicolumn{2}{|c|}{ Winter-Summer RR by gender } & \multicolumn{2}{|c|}{ Winter-Summer RR by age } & \multicolumn{2}{|c|}{ Winter-Summer RR by Race } \\
\hline & $\begin{array}{l}\text { RR }(95 \% \text { CI }) \\
\text { Men }\end{array}$ & RR $(95 \%$ CI) & $\begin{array}{l}\text { RR }(95 \% \mathrm{CI}) \\
\text { Younger }(65-80)\end{array}$ & $\begin{array}{l}\text { RR }(95 \% \text { CI }) \\
\text { Older }(>80)\end{array}$ & $\begin{array}{l}\text { RR }(95 \% \text { CI }) \\
\text { White Individuls }\end{array}$ & RR $(95 \% \mathrm{CI})$ \\
\hline Hip & $1.15[1.08-1.23]$ & $1.07[1.03-1.10]^{*}$ & $1.10[1.05-1.15]$ & $1.08[1.04-1.12]$ & $1.08[1.05-1.12]$ & $1.21[1.03-1.42]$ \\
\hline Distal forearm & $1.51[1.33-1.71]$ & $1.15[1.11-1.21]^{* * *}$ & $1.25[1.19-1.32])$ & $1.08[1.00-1.16]^{* *}$ & $1.20[1.15-1.25]$ & $1.05[0.81-1.37]$ \\
\hline Proximal humerus & $1.23[1.07-1.42]$ & $1.19[1.12-1.27]$ & $1.28[1.19-1.38]$ & $1.10[1.01-1.20]^{* *}$ & $1.19[1.12-1.26]$ & $1.50[1.02-2.20]$ \\
\hline Ankle & $1.25[1.10-1.42]$ & $1.21[1.13-1.29]$ & $1.23[1.15-1.31]$ & 1.18 [1.04-1. 34] & $1.22[1.14-1.29]$ & $1.30[1.01-1.68]$ \\
\hline
\end{tabular}

RRs are based on Poisson regression models. The models by gender included age and race, the models by age included gender and race, and the model by race included gender and age. Stars indicate level of significance of difference by gender, age, and race in regard to winter-summer relative fracture risk: ${ }^{*} \mathrm{p}<0.05 ; * * \mathrm{p}<0.01 ; * * * \mathrm{p}<0.001$.

frequently, as expected in the more robust population groups, may increase an older person's opportunity to fall $[39,40]$.

The protective association of sunshine with risk of hip fracture in the summer and fall may be due to the higher serum concentrations of 25-hydroxyvitamin D associated with sun exposure [41, 42]. Improved vitamin D status through supplementation with vitamin D may reduce the risk of falls [25], improve bone mineral density [43] and reduce risk of fractures $[26,27,43]$ in older individuals. On the other hand, for the fractures outside the hip, an incremental gain in vitamin $\mathrm{D}$ from sunlight exposure may be out-weighed by the increased risk associated with out-door activities in more active older persons in sunny weather. In the winter, the lack of association between sunshine pattern and risk of fractures at all studied fracture sites may be explained by the lower effectiveness of winter sunshine in substantially increasing 25hydroxyvitamin D levels in comparison to summer sun $[44,45]$.

The strengths of our study are its population-based design and the inclusion of fractures of the hip and other sites. The large sample size provided sufficient power for stratification by gender, age group and warm and cold climate states. The weather data stem from a large national weather website that we were able to integrate with our fracture data by state. In addition, we were able to adjust the analyses for important demographic variables and determinants of fracture risk, including gender, age and race/ethnicity.

An advantage of using earlier Medicare data for these analyses is that in the period 1986-1990, only about $4-5 \%$ of Medicare recipients aged 65+ were in an HMO. By 2000 , this proportion had grown to approximately $19 \%$, with much higher penetration in some states, especially in the West [46]. Since it is necessary to exclude Medicare beneficiaries enrolled in HMOs in analyses such as ours, this level of HMO penetration would have limited the generalizability of analyses conducted with later data.

There are also potential limitations to our study. Our case definitions depended critically on the validity of Medicare claims data, which may not be entirely accurate. However, Medicare data have high validity both for hip fracture [47, 48] and other fractures [47]. Misclassification of exposure data is also a possibility. The sunshine, temperature, and snowfall data we used were state averages and might not have represented the actual experience of individuals living in areas with more extreme weather. Such misclassification would likely be random and thus bias our results towards the null. Furthermore, we found very similar results if our analyses were restricted to weather information from the capital cities. Finally, the fracture cases in our study were largely white and female, and our findings pertain most directly to this fracture-prone group. However, we found that winter incidence peaks are present also in men and black individuals, and for some fracture sites the winter peaks were even more pronounced in these subgroups of the population.

In summary, we show that fractures at the hip, distal forearm, proximal humerus and ankle contribute considerably to winter morbidity in older individuals. However, the degree of seasonality of fracture risk is smaller for hip fractures than for the non-hip fractures. Still, the observed marked winter peak of both hip and non-hip fractures suggests that minimizing environmental hazards in the winter may be particularly important from a public health point of view. Preventive efforts should extend to individuals living in warm climate states, as their winter fracture risk is not reduced compared to summer, or- for non-hip fractures- may even be more pronounced. Men, and individuals younger than 80 may also be at increased winter fracture risk. This may be due to increased exposure to winter weather among this more robust population group. 


\section{a}

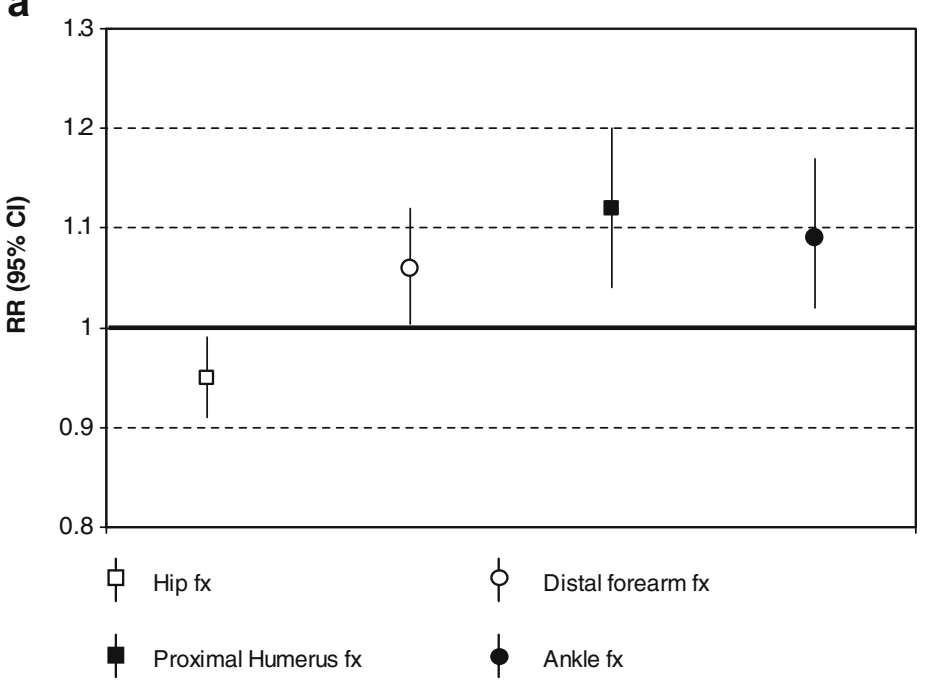

b

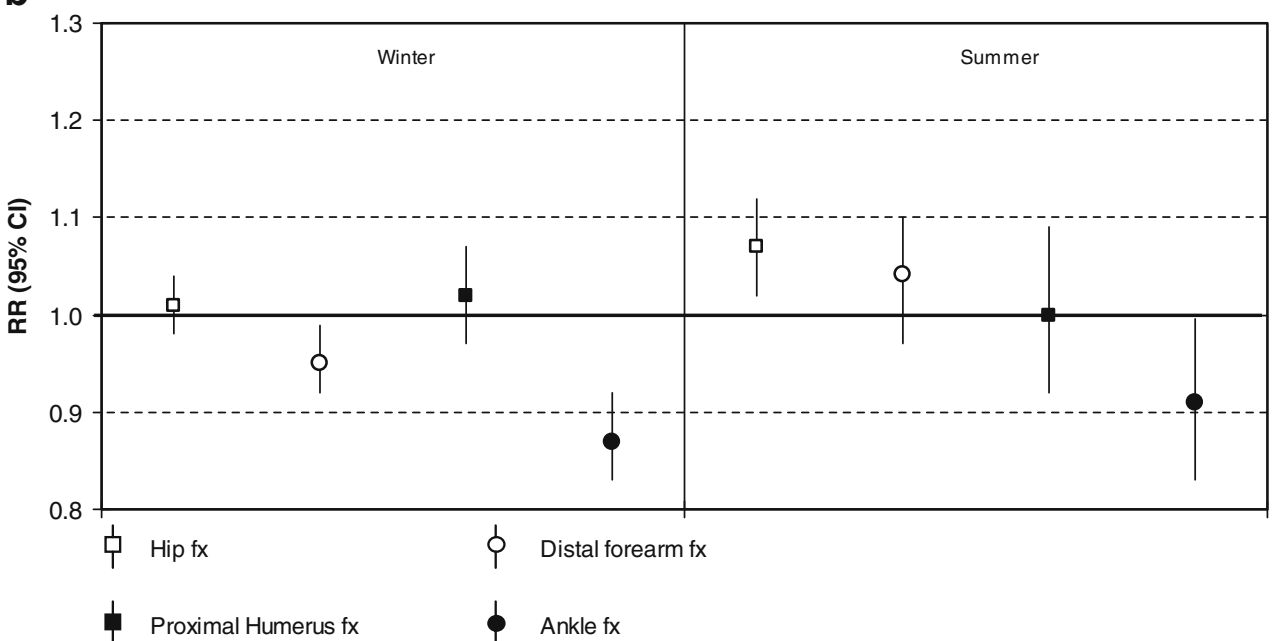

C

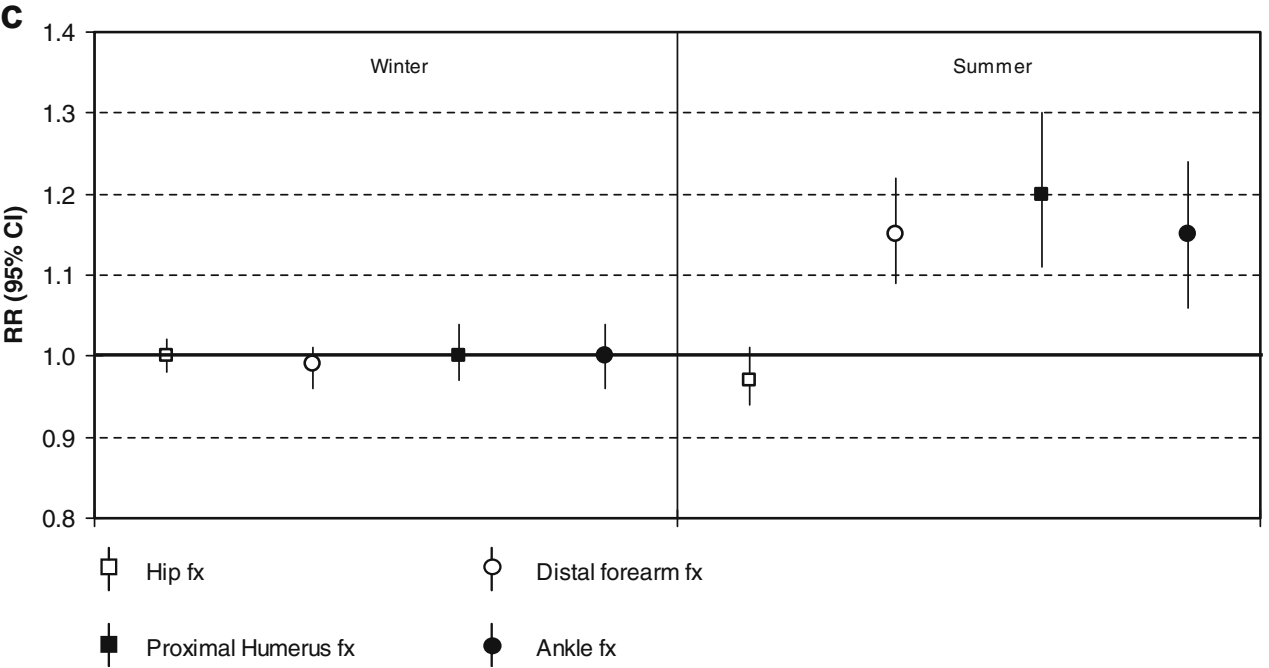

Fig. 3 Association between weather and fracture risk in winter and summer. a) Relative risks for fracture per 20 inches (50.8 centimeters) snowfall in winter. RRs are based on Poisson regression models adjusted for age, gender, race/ethnicity, sunny days and temperature. b) Relative risks for fractures per 10 degrees Fahrenheit (5.6 degrees Celsius) in

adjusted for age, gender and race/ethnicity, snowfall and sunshine in winter, and sunshine in summer. c) Relative risks for fractures per 14 sunny days in winter and summer. RRs are based on Poisson regression models adjusted for age, gender, race/ethnicity and temperature in both seasons, plus for snowfall in winter 


\section{References}

1. Douglas AS, Allan TM, Rawles JM (1991) Composition of seasonality of disease. Scott Med J 36(3):76-82

2. Wilkinson P, Pattenden S, Armstrong B et al (2004) Vulnerability to winter mortality in elderly people in Britain: population based study. BMJ 17:17

3. Wilkinson P, Pattenden S, Armstrong B et al (2004) Vulnerability to winter mortality in elderly people in Britain: population based study. BMJ 329(7467):647, Epub 2004 Aug 17

4. Lieberman D, Friger MD (1999) Seasonal variation in hospital admissions for community-acquired pneumonia: a 5-year study. J Infect 39(2): 134-140

5. Vilkman S, Keistinen T, Tuuponen T, Kivela SL (1996) Seasonal variation in hospital admissions for chronic obstructive pulmonary disease in Finland. Arctic Med Res 55(4):182-186

6. Spencer FA, Goldberg RJ, Becker RC, Gore JM (1998) Seasonal distribution of acute myocardial infarction in the second National Registry of Myocardial Infarction. J Am Coll Cardiol 31(6):12261233

7. Jacobsen SJ, Sargent DJ, Atkinson EJ, O'Fallon WM, Melton LJ 3rd (1995) Population-based study of the contribution of weather to hip fracture seasonality. Am J Epidemiol 141(1):79-83

8. Bulajic-Kopjar M (2000) Seasonal variations in incidence of fractures among elderly people. Inj Prev 6(1):16-19

9. Hemenway D, Colditz GA (1990) The effect of climate on fractures and deaths due to falls among white women. Accident Anal Prev 22(1):59-65

10. Jacobsen SJ, Goldberg J, Miles TP, Brody JA, Stiers W, Rimm AA (1991) Seasonal variation in the incidence of hip fracture among white persons aged 65 years and older in the United States, 1984-1987. Am J Epidemiol 133(10):996-1004

11. Lau EM, Gillespie BG, Valenti L, O'Connell D (1995) The seasonality of hip fracture and its relationship with weather conditions in New South Wales. Aust J Public Health 19(1):76-80

12. Mannius S, Mellstrom D, Oden A, Rundgren A, Zetterberg C (1987) Incidence of hip fracture in western Sweden 1974-1982. Comparison of rural and urban populations. Acta Orthop Scand 58 (1):38-42

13. Zetterberg C, Andersson GB (1982) Fractures of the proximal end of the femur in Goteborg, Sweden, 1940-1979. Acta Orthop Scand 53(3):419-426

14. Jacobsen SJ, Sargent DJ, Atkinson EJ, O'Fallon WM, Melton LJ 3rd (1999) Contribution of weather to the seasonality of distal forearm fractures: a population-based study in Rochester, Minnesota. Osteoporos Int 9(3):254-259

15. Ralis ZA (1981) Epidemic of fractures during period of snow and ice. Br Med J (Clin Res Ed) 282(6264):603-605

16. O’Neill TW, Marsden D, Adams JE, Silman AJ (1996) Risk factors, falls, and fracture of the distal forearm in Manchester, UK. J Epidemiol Community Health 50(3):288-292

17. Graafmans WC, Ooms ME, Bezemer PD, Bouter LM, Lips P (1996) Different risk profiles for hip fractures and distal forearm fractures: a prospective study. Osteoporos Int 6(6):427-431

18. Keegan TH, Kelsey JL, King AC, Quesenberry CP Jr, Sidney S (2004) Characteristics of fallers who fracture at the foot, distal forearm, proximal humerus, pelvis, and shaft of the tibia/fibula compared with fallers who do not fracture. Am J Epidemiol 159(2):192-203

19. Nevitt MC, Cummings SR (1994) Type of fall and risk of hip and wrist fractures: the study of osteoporotic fractures. J Am Geriatr Soc 42(8):909

20. Carter SE, Campbell EM, Sanson-Fisher RW, Gillespie WJ (2000) Accidents in older people living at home: a community-based study assessing prevalence, type, location and injuries. Aust N Z J Public Health 24(6):633-636
21. Campbell AJ, Borrie MJ, Spears GF, Jackson SL, Brown JS, Fitzgerald JL (1990) Circumstances and consequences of falls experienced by a community population 70 years and over during a prospective study. Age Ageing 19(2):136-141

22. Bastow MD, Rawlings J, Allison SP (1983) Undernutrition, hypothermia, and injury in elderly women with fractured femur: an injury response to altered metabolism? Lancet 1(8317):143-146

23. Bischoff HA, Stahelin HB, Dick W et al (2003) Effects of vitamin $\mathrm{D}$ and calcium supplementation on falls: a randomized controlled trial. J Bone Miner Res 18(2):343-351

24. Bischoff-Ferrari HA, Orav EJ, Dawson-Hughes B (2006) Effect of cholecalciferol plus calcium on falling in ambulatory older men and women: a 3-year randomized controlled trial. Arch Intern Med 166(4):424-430

25. Bischoff-Ferrari HA, Dawson-Hughes B, Willett CW et al (2004) Effect of vitamin D on falls: a meta-analysis. JAMA 291 (16):1999-2006

26. Chapuy MC, Arlot ME, Duboeuf F et al (1992) Vitamin D3 and calcium to prevent hip fractures in the elderly women. $\mathrm{N}$ Engl J Med 327(23):1637-1642

27. Trivedi DP, Doll R, Khaw KT (2003) Effect of four monthly oral vitamin D3 (cholecalciferol) supplementation on fractures and mortality in men and women living in the community: randomised double blind controlled trial. BMJ 326(7387):469

28. Baron JA, Karagas M, Barrett J et al (1996) Basic epidemiology of fractures of the upper and lower limb among Americans over 65 years of age. Epidemiology 7(6):612-618

29. Karagas MR, Baron JA, Barrett JA, Jacobsen SJ (1996) Patterns of fracture among the United States elderly: geographic and fluoride effects. Ann Epidemiol 6(3):209-216

30. Fisher ES, Baron JA, Malenka DJ, Barrett J, Bubolz TA (1990) Overcoming potential pitfalls in the use of Medicare data for epidemiologic research. Am J Public Health 80(12):1487-1490

31. Barrett JA, Baron JA, Karagas MR, Beach ML (1999) Fracture risk in the U.S. Medicare population. J Clin Epidemiol 52(3):243-249

32. Baron JA, Barrett JA, Karagas MR (1996) The epidemiology of peripheral fractures. Bone 18(3 Suppl):209S-213S

33. Baron JA, Barrett J, Malenka D et al (1994) Racial differences in fracture risk. Epidemiology 5(1):42-47

34. Levy AR, Bensimon DR, Mayo NE, Leighton HG (1998) Inclement weather and the risk of hip fracture. Epidemiology 9 (2): $172-177$

35. Pedrazzoni M, Alfano FS, Malvi C, Ostanello F, Passeri M (1993) Seasonal variation in the incidence of hip fractures in EmiliaRomagna and Parma. Bone 14(Suppl 1):S57-S63

36. Holmberg S, Thorngren KG (1987) Statistical analysis of femoral neck fractures based on 3053 cases. Clin Orthop 218:32-41

37. Parker MJ, Martin S (1994) Falls, hip fractures and the weather. Eur J Epidemiol 10(4):441-442

38. Jacobsen SJ, Goldberg J, Miles TP, Brody JA, Stiers W, Rimm AA (1990) Regional variation in the incidence of hip fracture. US white women aged 65 years and older. JAMA 264(4):500-502

39. O’Loughlin JL, Robitaille Y, Boivin JF, Suissa S (1993) Incidence of and risk factors for falls and injurious falls among the community-dwelling elderly. Am J Epidemiol 137(3):342-354

40. Vellas BJ, Wayne SJ, Garry PJ, Baumgartner RN (1998) A twoyear longitudinal study of falls in 482 community-dwelling elderly adults. J Gerontol 53A:M264-M274

41. Holick MF (1985) The photobiology of vitamin D and its consequences for humans. Ann N Y Acad Sci 453:1-13

42. Harris SS, Dawson-Hughes B (1998) Seasonal changes in plasma 25-hydroxyvitamin D concentrations of young American black and white women. Am J Clin Nutr 67(6):1232-1236

43. Dawson-Hughes B, Harris SS, Krall EA, Dallal GE (1997) Effect of calcium and vitamin D supplementation on bone density in men and women 65 years of age or older. N Engl J Med 337(10):670-676 
44. Gordon CM, DePeter KC, Feldman HA, Grace E, Emans SJ (2004) Prevalence of vitamin D deficiency among healthy adolescents. Arch Pediatr Adolesc Med 158(6):531-537

45. Webb AR, Kline L, Holick MF (1988) Influence of season and latitude on the cutaneous synthesis of vitamin D3: exposure to winter sunlight in Boston and Edmonton will not promote vitamin D3 synthesis in human skin. J Clin Endocrinol Metab 67(2):373-378

46. Standing Committee on the Scientific Evaluation of Dietary Reference Intakes (1997) Dietary reference intakes: calcium, phosphorus, magnesium, vitamin D, and fluoride. National Academy Press, Washington, DC

47. Ray WA, Griffin MR, Fought RL, Adams ML (1992) Identification of fractures from computerized Medicare files. J Clin Epidemiol 45(7):703-714

48. Fisher ES, Whaley FS, Krushat WM et al (1992) The accuracy of Medicare's hospital claims data: progress has been made, but problems remain. Am J Public Health 82 (2):243-248 